\title{
Hydrothermal Saline Promoted Grafting of Periodic Mesoporous Organic Sulfonic Acid Silicas for Sustainable FAME Production
}

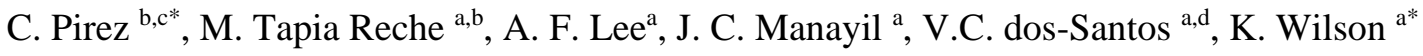 \\ ${ }^{a}$ European Bioenergy Research Institute, Aston University, Birmingham B4 7ET, UK. \\ ${ }^{b}$ School of Chemistry, Cardiff University, Cardiff CF10 3AT. \\ ${ }^{c}$ UCCS, University of Lille I, 59655 Villeneuve d'Ascq, France. \\ ${ }^{d}$ Lab of Bioinorganic Chemistry and Catalysis, Federal University of Paraná, CP 19081, CEP 81531-990, Curitiba, Paraná, Brazil \\ *Corresponding author: E-mail: k.wilson@aston.ac.uk
}

\begin{abstract}
Hydrothermal saline promoted grafting (HSPG) of sulfonic acid groups onto SBA-15 and periodic mesoporous organic (PMO) silica analogues affords solid acid catalysts with high acid site loadings $\left(>2.5 \quad \mathrm{mmol} . \mathrm{g}^{-1} \mathrm{H}^{+}\right)$, ordered mesoporosity and tunable hydrophobicity. The resulting catalysts show excellent activity for fatty acid esterification and tripalmitin transesterification to methyl palmitate, with framework phenyl groups promoting FAME production.
\end{abstract}

Keywords Heterogeneous Catalysis - Biodiesel - sulfonic acid - solid acid - esterification - transesterification - mesoporous materials

\section{Introduction}

Concern over climate change and fossil fuel depletion is driving academic and industrial research into alternative renewable energies. Future sustainable energy platforms will be diverse, spanning solar, wind and bioenergy, with biodiesel ranked in the top three alternative energies for transportation [1]. Biodiesel is commonly composed of fatty acid methyl esters (FAME) produced via the esterification and transesterification of free fatty acids (FFAs) and triacyl glycerides (TAGs) from plant, algae or waste oil sources. Current commercial practises employ homogeneous alkali or mineral acid catalysts to effect these transformations and consequently generate vast quantities of aqueous waste, detrimental to the economic feasibility and environmental impact of biodiesel synthesis. Solid acid catalysts able to perform these esterification and transesterification reactions simultaneously under mild conditions would be particularly desirable to minimise processing steps and permit the use of high FFA containing waste oils.

A range of solid acids including protonated zeolites, acid ion-exchange resins, sulfonic acid mesostructured silicas, sulfonated carbons, heteropolyacids, sulfated zirconia and acidic ionic liquids have been studied for biodiesel synthesis [2],[3]. The performance of such materials is dictated by the strength and accessibility of active acid sites to bulky FFA and
TAG components, and the surface energy of the support which will regulate reactant/product binding. In-pore mass transport and active site accessibility can be improved in mesoporous silicas via e.g. pore expansion of SBA-15 [4], the use of interconnected pore networks such as KIT-6 [5], or the incorporation of macropores in hierarchically ordered macroporous-mesoporous SBA-15 [6]. Surface polarity is less frequently addressed, but also influences esterification and transesterification reactions, which are both reversible processes, with reactively-formed water and glycerol driving the respective reverse reactions. TAG fatty acid chains may also restrict molecular mobility through polar porous acid catalysts, with in-pore diffusion favoured by more hydrophobic pore environments. The hydrophobicity of sulfonic acid silicas has been tuned via organic surface co-functionalisation to enhance FFA esterification [7]. However, such approaches are hampered by low acid site loadings due to competition for surface silanols by acid functions and inert hydrophobic surface modifiers [8]. Periodic Mesoporous Organic (PMO) silicas [1, 9] [10],[11] are similar to conventional mesoporous silicas, but incorporate organic bridging functions (OR) $3-\mathrm{Si}-\mathrm{R}^{\prime}-\mathrm{Si}-(\mathrm{OR})_{3}$, where $\mathrm{R}^{\prime}$ can be $\mathrm{CH}_{2}, \mathrm{C}_{2} \mathrm{H}_{5}, \mathrm{C}_{2} \mathrm{H}_{4}$, benzene, biphenyl or thiophene [12], and therefore exhibit tunable hydrophobicity [13]. Hydrothermally stable PMO silicas with framework aryl groups can be prepared with a hexagonally ordered mesopore network [9], which are attractive for catalytic applications [14].

Sulfonic acid functionalised PMO materials have been explored for a range of reactions spanning condensation [15], etherification [16] and esterification [17]. The hydrophobic nature of such PMOs is claimed to promote water removal from the active acid sites, and indeed dispersive surface energies (a quantitative measure of hydrophobicity) determined by Inverse GC proved an accurate predictor of palmitic acid esterification activity [17]. However, the low acid site loading and resultant poor conversions have hampered the practical application of these acid functionalised PMOs. We recently described a postsynthetic, hydrothermal saline grafting method (HSPG), which 
offer far higher sulfonic acid loadings than achievable by conventional one pot, or toluene grafting routes [18]. Grafting from saline solution is believed to hydrolyse $\mathrm{Si}-\mathrm{O}-\mathrm{Si}$ bridges to increase the density of surface silanols available for functionalising. PMO-benzene prepared using 1,4bis(triethoxysilyl)benzene (BTSB) has good hydrothermal stability [19],[20], and hence its modification via the HSPG method is an attractive route to create a hydrophobic catalyst possessing a high density of acid sites. Here we report the application of HSPG to form tunable, high activity sulfonic acid SBA-PMO materials for FFA esterification and TAG transesterification, pertinent to biodiesel production.

\section{Experimental}

\subsection{Catalyst synthesis}

SBA-15 and PMO analogues containing different levels of BTSB phenyl bridged silane (25, 50, 75 and $100 \mathrm{wt} \%)$ were prepared adapting the protocol of Sánchez-Vázquez et al [21], in which the $\mathrm{HCl}$ concentration (Fisher 36wt\%) was decreased to improve the uniformity of the pore channels. Note that $S B A$ $B T S B 0 \% \equiv S B A-15$. Briefly, $3 \mathrm{~g}$ of Pluronic P123 triblock copolymer was dissolved in $96 \mathrm{~cm}^{3}$ of water and $1 \mathrm{~cm}^{3}$ of $\mathrm{HCl}$ under stirring at $40{ }^{\circ} \mathrm{C}$. The appropriate ratio of TEOS and BTSB precursor was subsequently added to the surfactant solution (see Table S1 ESI), which was stirred at $40{ }^{\circ} \mathrm{C}$ for a further $72 \mathrm{~h}$. The mixture was then aged at $130{ }^{\circ} \mathrm{C}$ for $24 \mathrm{~h}$ and the resulting solid product filtered, washed three times with deionised water and dried at room temperature. Residual P123 template was extracted via two cycles of a $24 \mathrm{~h}$ reflux with EtOH/1 $\mathrm{M} \mathrm{HCl}$ solution, then filtered and dried to afford the final powdered SBA-15 and PMO silica supports.

Silicas were subsequently functionalised with propyl sulfonic acid employing our recently reported HSPG method [18]. $1 \mathrm{~g}$ of material was mixed in $30 \mathrm{~cm}^{3} \mathrm{H}_{2} \mathrm{O}$ with $200 \mathrm{mg}$ of $\mathrm{NaCl}$ for $15 \mathrm{~min}$ at $\mathrm{RT}$, after which $1 \mathrm{~cm}^{3}$ of mercaptopropyl trimethoxysilane (MPTS) (95\% Sigma Aldrich) was added, and the suspension refluxed at $100{ }^{\circ} \mathrm{C}$ under stirring for $24 \mathrm{~h}$. The resulting thiol-functionalised solid was filtered, washed three times with deionised $\mathrm{H}_{2} \mathrm{O}$ and dried at room temperature. Thiol groups were converted into $-\mathrm{SO}_{3} \mathrm{H}$ by mild oxidation with 30 $\mathrm{cm}^{3}$ of $30 \%$ hydrogen peroxide (Sigma-Aldrich) by continuous stirring at room temperature for $24 \mathrm{~h}$. The resulting functionalised solid was filtered, washed three times with water, and dried and stored at room temperature.

\subsection{Catalyst characterisation}

Nitrogen porosimetry was measured using a Quantachrome Nova 2000e porosimeter using NOVAWin software. Samples were degassed at $120{ }^{\circ} \mathrm{C}$ for $2 \mathrm{~h}$ before analysis by $\mathrm{N}_{2}$ adsorption at $-196^{\circ} \mathrm{C}$. BET surface areas were calculated over the relative pressure range $0.01-0.2$. Pore diameters and volumes were calculated applying the $\mathrm{BJH}$ method to the desorption isotherm for relative pressures $>0.35$. Low angle powder XRD patterns were recorded on a PANalytical
X'pertPro diffractometer fitted with an X'celerator detector and $\mathrm{Cu} \mathrm{K \alpha}\left(\begin{array}{ll}1.54 & \AA\end{array}\right)$ source calibrated against a Si standard (PANalytical). Low angle patterns were recorded for $2 \theta=0.3-$ $6^{\circ}$ with a step size of $0.01^{\circ}$.

HRTEM measurements were obtained with a JEOL 2100 transmission electron microscope operated at $200 \mathrm{kV}$, with images recorded by a Gatan Ultrascan 1000XP digital camera. Image analysis was undertaken using ImageJ software. XPS was performed using a Kratos Axis HSi X-ray photoelectron spectrometer fitted with a charge neutraliser and magnetic focusing lens employing $\mathrm{Al} \mathrm{K}_{\alpha}$ monochromated radiation (1486.6 eV). Surface analysis was undertaken on Shirley background-subtracted spectra, applying the appropriate instrument and element-specific response factors. Spectral fitting was conducted using CasaXPS version 2.3.14, with binding energies corrected to the $\mathrm{C} 1 \mathrm{~s}$ peak at $284.8 \mathrm{eV}$ and high resolution $\mathrm{C} 1 \mathrm{~s}, \mathrm{O} 1 \mathrm{~s}, \mathrm{~S} 2 \mathrm{p}$ and $\mathrm{Si} 2 \mathrm{p}$ XP spectra fitted using a common Gaussian/Lorentzian peak shape. Errors were estimated by varying the Shirley background subtraction procedure across reasonable limits and re-calculating fits. Thermogravimetric analysis (TGA) was performed using a Stanton Redcroft STA780 thermal analyser. 10-20 mg samples were heated at $10{ }^{\circ} \mathrm{C} \mathrm{min}{ }^{-1}$ under a $20 \mathrm{~cm}^{3} \cdot \mathrm{min}^{-1}$ flow of 20 vol\% $\mathrm{O}_{2}$ in helium. Acid site titrations were performed via $\mathrm{NH}_{3}$ pulse chemisorption using a Quantachrome ChemBET 3000 instrument. Samples were degassed at $150{ }^{\circ} \mathrm{C}$, after which $\mathrm{NH}_{3}$ pulses were introduced at $100{ }^{\circ} \mathrm{C}$ until saturation was achieved. $\mathrm{NH}_{3}$ TPD was performed by heating from $100-800{ }^{\circ} \mathrm{C}$ using heating rate of $10{ }^{\circ} \mathrm{C} \cdot \mathrm{min}^{-1}$ and a MKS Minilab mass spectrometer to follow $\mathrm{m} / \mathrm{z}=15,16$ and 17. DRIFT spectra were obtained using a Nicolet Avatar 370 MCT with Smart Collector accessory, mid/near infrared source and a liquid $\mathrm{N}_{2}$ cooled MCT detector. Samples were diluted with $\mathrm{KBr}$ powder (5 wt\% in $\mathrm{KBr}$ ) for analysis, loaded into an environmental cell and dried in vacuo at $200{ }^{\circ} \mathrm{C}$ for $2 \mathrm{~h}$ prior to measurements. ${ }^{1} \mathrm{H},{ }^{13} \mathrm{C}$, and ${ }^{29} \mathrm{Si} \mathrm{CP}-\mathrm{MAS}-\mathrm{NMR}$ was conducted at the EPSRC UK National Solid-state NMR Service (University of Durham). ${ }^{13} \mathrm{C}$ and ${ }^{29} \mathrm{Si}$ spectra were recorded at 79.44 and $100.56 \mathrm{MHz}$, respectively, using a Varian VNMRS spectrometer and a $6 \mathrm{~mm}$ (rotor o.d.) magic-angle spinning (MAS) probe. Spectra were obtained using cross-polarisation with a $3 \mathrm{~ms}$ contact time, at ambient probe temperature $\left(\sim 25^{\circ} \mathrm{C}\right)$ and a sample spin-rate of 6 $\mathrm{kHz} .{ }^{13} \mathrm{C}$ spectra were recorded with a $5 \mathrm{~s}$ recycle delay with 168-302 repetitions accumulated. Spectral referencing was performed using an external sample of neat tetramethylsilane (TMS), and setting the high-frequency signal from adamantane to $38.5 \mathrm{ppm}$. Silicon spectra were obtained with a $1 \mathrm{~s}$ recycle delay and between 1520 and 6200 repetitions were accumulated. ${ }^{29} \mathrm{Si}$ spectral referencing was with respect to an external sample of neat TMS and setting the high-frequency signal from tetrakis(trimethylsilyl)methane to $-9.9 \mathrm{ppm}$.

Solid-state ${ }^{1} \mathrm{H}$ spectra were recorded at $400.18 \mathrm{MHz}$ using a Bruker Avance III HD spectrometer and a $1.9 \mathrm{~mm}$ (rotor o.d.) MAS probe. Spectra were obtained using direct-excitation with a DEPTH background suppression pulse sequence utilising 90 and $180^{\circ}$ pulses of 3 and $6 \mathrm{~ms}$ duration, respectively. A recycle 
delay of $1 \mathrm{~s}$, at a sample spin-rate of $40 \mathrm{kHz}$, was employed with 64 repetitions accumulated. Spectral referencing was with respect to an external sample of neat TMS and setting the signal from adamantane to $1.9 \mathrm{ppm}$.

\subsection{Catalyst activity}

Esterification reactions were performed a stirred batch reactor using a Radley's carousel at $60{ }^{\circ} \mathrm{C}$. $10 \mathrm{mmol}$ of palmitic acid (Sigma Aldrich $>99 \%$ ) was reacted in $12.5 \mathrm{~cm}^{3}$ methanol (Fisher 99\%) (molar ratio $\mathrm{nMeOH} /$ nacid $=30)$ using $50 \mathrm{mg}$ catalyst and $0.6 \mathrm{~cm}^{3}(2.5 \mathrm{mmol})$ of dihexylether (Sigma Aldrich $97 \%$ ) as an internal standard. The effect of water was studied via addition of $20 \mathrm{wt} \%$ of $\mathrm{H}_{2} \mathrm{O}$ (relative to the weight of palmitic acid). Reaction profiles were obtained via periodic sampling and off-line GC analysis, with product calibration curves used to verify mass balances (all >98\%). Catalytic profiles were an average of two separate runs, with samples analysed in triplicate. Esterification was monitored using a Varian 450-GC equipped with a CP-Sil 5 CB $15 \mathrm{~m}$ x $0.25 \mathrm{~mm}$ x $0.25 \mu \mathrm{m}$ capillary column. Dichloromethane was used to dilute samples for GC analysis. Turnover frequencies (TOF) were determined from the linear portion of the initial reaction rate profile for conversions $<25 \%$, and normalized to the acid site concentration determined from $\mathrm{NH}_{3}$ titration. To aid catalyst separation and increase the accuracy with which catalyst activity was assessed during recycling, propanonic acid esterification with methanol was employed as a test reaction to evaluate sulfonic acid stability. Reactions were performed as above at $60^{\circ} \mathrm{C}$, using $50 \mathrm{mg}$ catalyst with $10 \mathrm{mmol}$ propanoic acid (Sigma Aldrich $\geq 99.5$ ), $300 \mathrm{mmol}$ methanol and $0.5 \mathrm{mmol}$ dihexyl ether as an internal standard. The catalyst was recovered after $6 \mathrm{~h}$ reaction by centrifugation, washed with methanol, and dried in air at $80{ }^{\circ} \mathrm{C}$. The quantity of reactants using in the subsequent reaction was scaled according to the mass of recovered catalyst.

Glyceryl tripalmitate (Sigma Aldrich > 85\%) transesterification was carried out in a $50 \mathrm{ml}$ glass pressure flask under stirring at $80{ }^{\circ} \mathrm{C}$. $10 \mathrm{mmol}$ of tripalmitate $\left(\mathrm{C}_{16}\right)$ was dissolved in a mixture of $12.5 \mathrm{~cm}^{3}$ methanol $/ 12.5 \mathrm{~cm}^{3}$ butanol (to avoid the formation of a biphasic reaction mixture). Subsequently, $50 \mathrm{mg}$ of catalyst and $0.3 \mathrm{~cm}^{3}$ of dihexylether internal standard were added, and transesterification conducted for $24 \mathrm{~h}$ after which the reaction composition was determined using a Varian 450-GC equipped with a 1079 programmable direct on-column injector and Phenomenex capillary column (ZB-1HT Inferno $15 \mathrm{~m}$ x $0.53 \mathrm{~mm} \times 0.15 \mu \mathrm{m}$ ).

\section{Results and Discussion}

\subsection{Catalyst characterisation}

The family of SBA-BTSB materials with $\mathrm{BTSB} /(\mathrm{BTSB}+\mathrm{TEOS})$ ratios spanning 0 to $100 \mathrm{wt} \%$ were characterized by porosimetry, XRD, TGA, HRTEM, Raman and DRIFTS(Figs. S1-8) to verify the retention of ordered pore structure, degree of carbon incorporation, and the integrity of aromatic groups as a function of BTSB content. All materials exhibited type IV isotherms with $\mathrm{H} 1$ hysteresis, confirming the formation of mesoporous materials with a uniform pore distribution; specific surface areas decreased slightly with BTSB content (Table S2). XRD confirmed the formation of p6mm 2D hexagonal mesostructure in all cases, akin to that of siliceous SBA-15. The carbon content calculated from combustion of the benzyl bridging groups during TGA under oxygen (Fig. S4) increases linearly with BTSB content in the synthesis (Fig. S5). DRIFT and Raman spectroscopies (Fig. S6 and S7) confirmed the presence of phenyl groups, with Raman bands at $1597 \mathrm{~cm}^{-1}$ ( $v_{\text {ring }}$ ), 1210, $1107 \mathrm{~cm}^{-1}$ (ring breathing) and $634 \mathrm{~cm}^{-1}\left(\delta_{\text {ring }}\right)$, increasing with BTSB content; the vibrational mode, at $590 \mathrm{~cm}^{-1}$ has been assigned to $\delta \mathrm{Si-O}-\mathrm{H}$ modes [22]. The bands at 3040, 1270 and $1415 \mathrm{~cm}^{-1}$ in DRIFTS also increased with BTSB content, and are assigned to $\mathrm{C}-\mathrm{H}$ vibrations and stretching modes of phenyl bridging groups, while the band at $1620 \mathrm{~cm}^{-1}$ is attributed to $\mathrm{C}=\mathrm{C}$ vibrations [23].

HRTEM, porosimetry and XRD (Fig. S9-11) of sulfonic acid functionalised SBA-BTSB supports confirmed these hybrid inorganic-organic materials retained their ordered mesopore network, although sulfonic acid functionalization induced a slight decrease in mesopore diameter and total surface area (Table 1 and Fig 1). Raman confirmed that framework phenyl groups were unaffected after sulfonic acid grafting, while the appearance of new bands at 820 ( $v$ C-S $), 1050\left(v_{s} \mathrm{SO}_{3}\right)$ in Fig. $\mathbf{S 1 2}$ are consistent with $-\mathrm{SO}_{\mathrm{x}}$ modes [9],[15]. This is further supported by XPS which reveals an unresolved $S 2 p$ doublet centred around $169 \mathrm{eV}$, characteristic of $\mathrm{SO}_{3} \mathrm{H}$ (Fig. S13).

Table 1 Textural and acid properties of $\mathrm{PrSO}_{3} \mathrm{H} / \mathrm{SBA}-\mathrm{BTSB}$ catalysts as a function of framework aryl group content.

\begin{tabular}{|c|c|c|c|c|c|c|c|}
\hline $\begin{array}{c}\text { BTSB } \\
\text { content } \\
/ \mathrm{wt} \%\end{array}$ & $\begin{array}{c}\mathrm{C} \\
\text { loading } \\
/ \mathrm{wt} \%\end{array}$ & $\begin{array}{l}\text { Surface } \\
\text { area } \\
/ \mathrm{m}^{2} \cdot \mathrm{g}^{-1}\end{array}$ & $\begin{array}{l}\text { Mesopore } \\
\text { diameter } \\
/ / \mathrm{nm}\end{array}$ & $\begin{array}{l}\text { Unit } \\
\text { cell }^{\mathrm{c}} \\
/ \mathrm{nm}\end{array}$ & $\begin{array}{c}\mathrm{S} \\
\text { loading }^{\mathrm{d}} \\
/ \mathrm{wt} \%\end{array}$ & $\begin{array}{c}\text { Acid } \\
\text { loading } \\
\text { / } \mathrm{mmol}^{\mathrm{g}} \mathrm{g}^{-1}\end{array}$ & $\begin{array}{l}\text { Acid } \\
\text { density } \\
/ \mathrm{nm}^{-2}\end{array}$ \\
\hline 0 & 25 & 496 & 6.2 & 10.9 & 4.3 & 1.6 & 2.1 \\
\hline 25 & 11.2 & 572 & 5.4 & 10.4 & 4.3 & 1.6 & 1.7 \\
\hline 50 & 16.6 & 506 & 3.7 & 10.3 & 5.0 & 1.9 & 1.6 \\
\hline 75 & 21.4 & 432 & 3.7 & 10.4 & 5.3 & 2.1 & 2.5 \\
\hline 100 & 26.8 & 334 & 3.7 & 10.6 & 5.6 & 2.3 & 4.4 \\
\hline
\end{tabular}

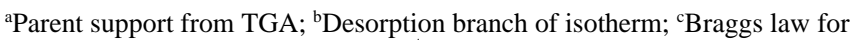
the (100) reflection and $\mathrm{a}_{0}=\left(2 \mathrm{~d}_{100}\right) / \sqrt{3} ;{ }^{\mathrm{d}} \mathrm{XPS} ;{ }^{\mathrm{e}} \mathrm{NH}_{3}$ pulse titration.

DRIFTS (Fig. S14) confirmed the loss of isolated and terminal $\mathrm{Si}-\mathrm{OH}$ and geminal $\mathrm{Si}-(\mathrm{OH})_{2}$ bands at $3727-3697 \mathrm{~cm}^{-1}$ following HSPG treatment, consistent with the surface attachment of sulfonic acid groups. ${ }^{13} \mathrm{C}$ and ${ }^{29} \mathrm{Si} \mathrm{CP}-\mathrm{MAS}-$ NMR provided further insight into the nature of the grafted species formed on the SBA-BTSB materials; ${ }^{13} \mathrm{C}$ spectra (Fig. S15) exhibited resonances characteristic of propyl sulfonic acid, with those at 12 and $18 \mathrm{ppm}$ associated with the $\mathrm{CH}_{2}-\mathrm{Si}$ and the methylene $-\mathbf{C H}_{2}$ - function respectively, while that at $54 \mathrm{ppm}$ is due to the $\mathrm{CH}_{2}-\mathrm{SO}_{3} \mathrm{H}$ group. The absence of a $22 \mathrm{ppm}$ signal due to a $\mathbf{C H}_{2}-\mathrm{SH}$ confirms the latter's complete oxidation by $\mathrm{H}_{2} \mathrm{O}_{2}[14 \mathrm{a}, 16]$. 
a)
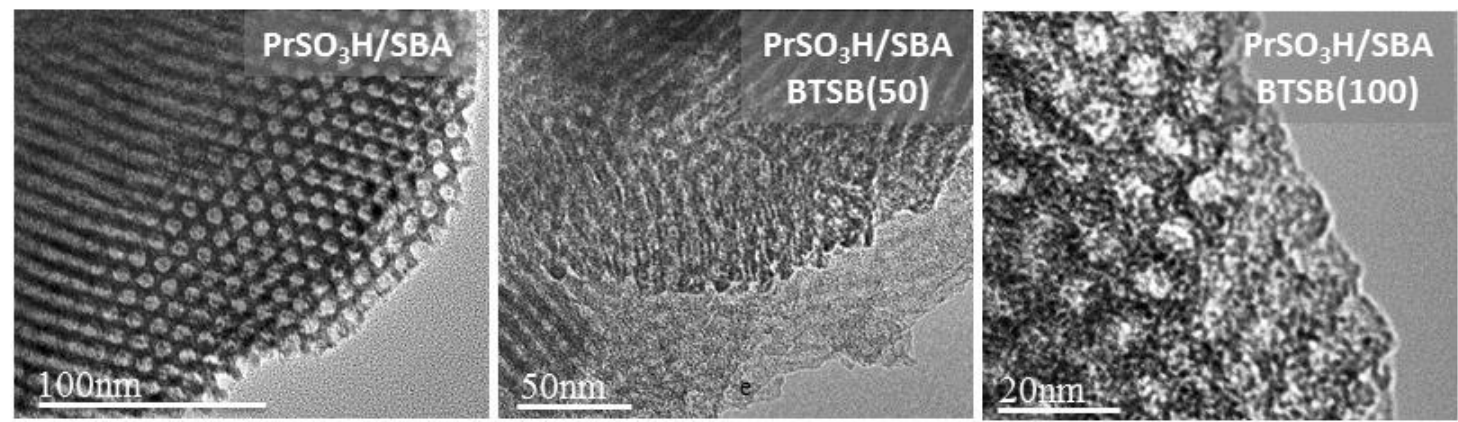

b)

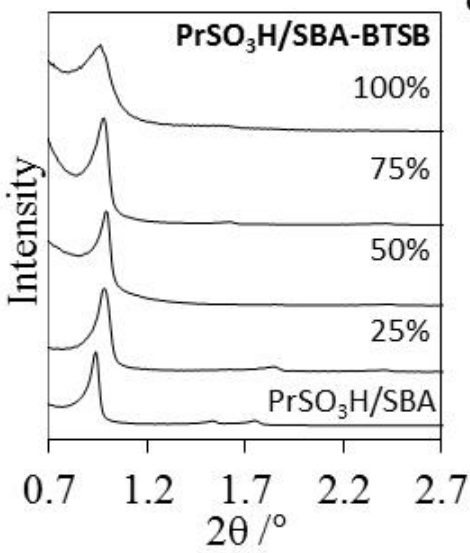

c)

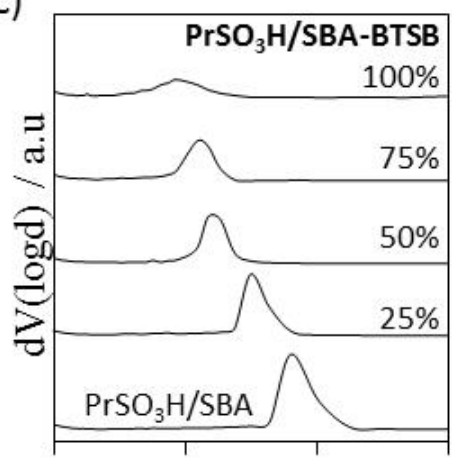

1
5

Pore diameter /nm d)

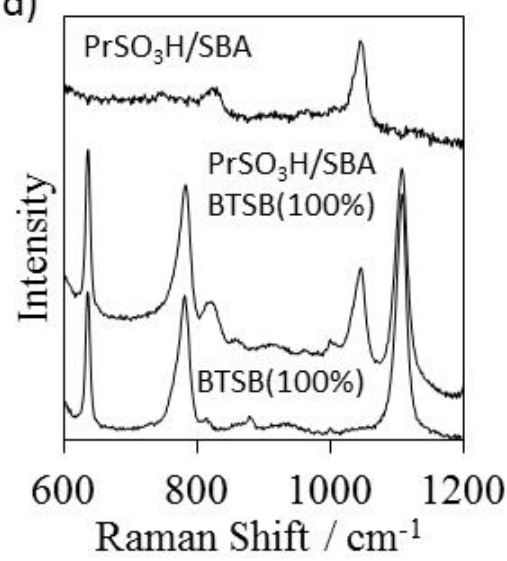

Fig. 1. (a) TEM, (b) low angle XRD, (c) porosimetry and (d) Raman spectra of sulfonic acid PMOs as a function of framework organic content.

${ }^{29} \mathrm{Si}$ NMR spectra (Fig. S16) exhibited resonances at $-90,-104-$ $109 \mathrm{ppm}$ for $\mathrm{Q}_{2}, \mathrm{Q}_{3}$ and $\mathrm{Q}_{4}$ peaks which are attributed to geminal $(\mathrm{HO})_{2} \mathrm{Si}(\mathrm{OSi})_{2}$, isolated silanols $(\mathrm{HO}) \mathrm{Si}(\mathrm{OSi})_{3}$ and $\mathrm{Si}(\mathrm{OSi})_{4}$ functions respectively. Signals between -50 and -85 ppm corresponding to $T_{1}, T_{2}$ and $T_{3}$ species are attributed to phenylene bridging groups in the silicate walls, in addition to $\mathrm{T}_{2}$ and $\mathrm{T}_{3}$ species arising from the organosilane sulfonic acid bound to the SBA-BTSB surface [21].

The sulfonic acid loadings achievable through HSPG shown in Table 1 were significantly higher than those previously reported through toluene grafting, wherein loadings of only 0.03 and 0.2 mmol.g ${ }^{-1}$ were achieved for $\mathrm{PrSO}_{3} \mathrm{H} / \mathrm{SBA}-$ $\mathrm{BTSB}(50)$ and $\mathrm{PrSO}_{3} \mathrm{H} / \mathrm{SBA}$ respectively [17]. It is interesting to note that the sulfonic acid loading and concomitant acid site density can also be systematically tuned by varying the framework organic content during PMO synthesis (Fig. S17). This can be rationalised in the light of recent studies of surface silanol densities in ethene-PMO materials, which revealed that polycondensation of ethene-bridged silanes does not progress to completion because of the steric demands of forming six siloxane bridges, compared to only the four required for TEOS in forming a pure silicate [24]. Hence, BTSB condensation within SBA-BTSB materials is expected to increase the density of uncoordinated silanols available for subsequent sulfonic acid derivatisation relative to a conventional SBA-15 [14b].

Catalytic activity of the pure silica and hybrid SBA-BTSB materials was subsequently evaluated in the esterification of palmitic acid, and transesterification of glyceryl tripalmitate, with methanol. Palmitic acid esterification was performed at 60 ${ }^{\circ} \mathrm{C}$, with and without water addition to assess the impact of framework hydrophobisation upon catalyst water tolerance (Fig S18-19). Fig. 2a shows typical reaction profiles for $\mathrm{PrSO}_{3} \mathrm{H} / \mathrm{SBA}-\mathrm{BTSB} 0 \%$ and $\mathrm{PrSO}_{3} \mathrm{H} / \mathrm{SBA}-\mathrm{BTSB} 100 \%$ in palmitic acid esterification with and without $20 \mathrm{wt} \%$ water added at the start the reaction. Water addition suppressed esterification irrespective of the BTSB content, however the magnitude of this water poisoning, expressed as the ratio of TOF (with water):TOF (without water) decreased with increasing framework organic content (Fig. 2b). This performance is impressive under such challenging conditions, with the resultant conversion comparable to literature reports for hydrophobic catalysts exposed to only $1 \mathrm{wt} \%$ water [25].

Absolute TOFs for palmitic acid esterification were almost insensitive to the presence of framework organic groups, averaging $13 \mathrm{~h}^{-1}$ (Table 2), indicating a common acid strength for sulfonic acid groups grafted onto silanols coordinated to silica or phenyl framework units. The observed slight decrease in TOF observed across the series when hybridization increases is most likely attributed to the small reduction in pore size hindering diffusion of the bulky palmitic acid. We should note that palmitic acid conversions over these sulfonic acid SBABTSB catalysts (including the SBA-BTSB0\%, i.e. SBA-15 analogue) prepared via the HSPG method were at least five times higher than the best achievable via toluene grafting of sulfonic acid functions [17]. The stability of grafted sulfonic acid groups was also evaluated by assessing catalyst 
recyclability following propanoic acid esterification (Fig S20), which shows that activity is unchanged upon reuse with an initial rate of $3 \mathrm{mmolh}^{-1}$ maintained.
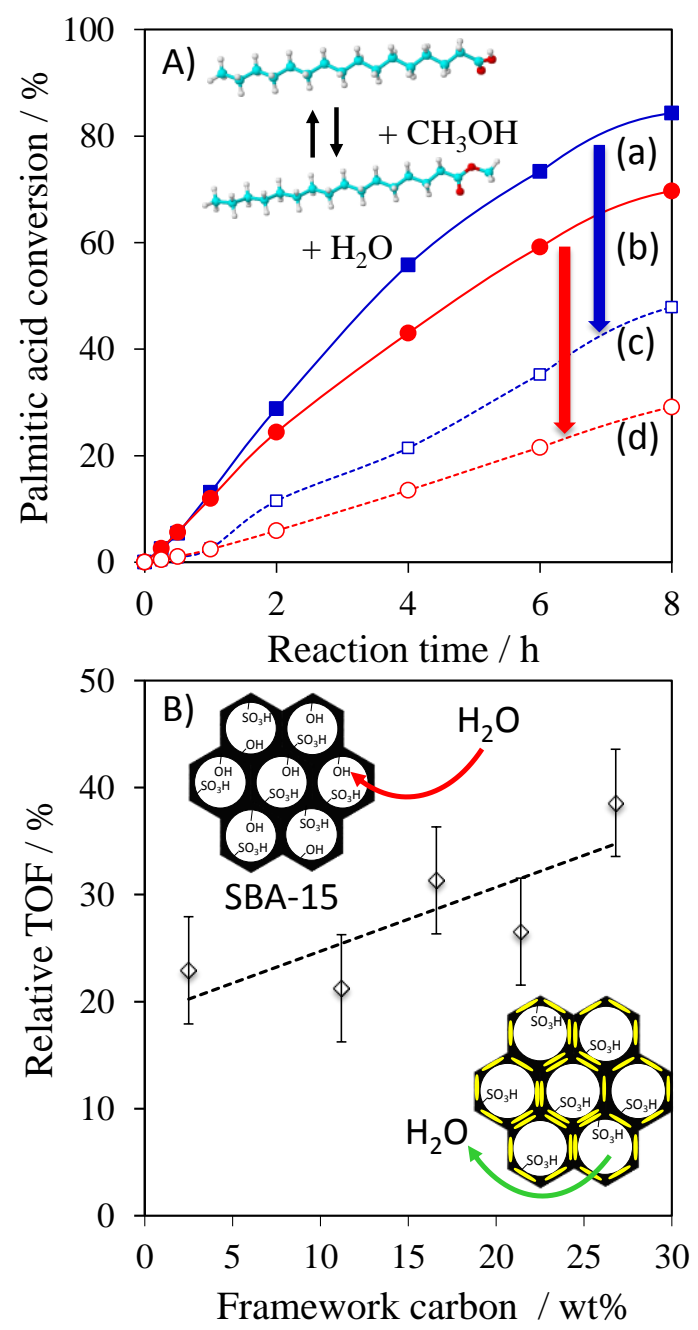

Fig. 2. (A) Palmitic acid esterification with methanol at $60{ }^{\circ} \mathrm{C}$ over (a) $\mathrm{RSO}_{3} \mathrm{H} / \mathrm{SBA}-\mathrm{BSTB} 100 \%$ (b) $\mathrm{RSO}_{3} \mathrm{H} / \mathrm{SBA}-\mathrm{BTSB} 0 \%$ (c) $\mathrm{RSO}_{3} \mathrm{H} / \mathrm{SBA}-$ BSTB $100 \%+\mathrm{H}_{2} \mathrm{O}$ (d) $\mathrm{RSO}_{3} \mathrm{H} / \mathrm{SBA}-\mathrm{BTSB} 0 \%+\mathrm{H}_{2} \mathrm{O}$. (B) Retained TOFs following $20 \mathrm{wt} \%$ water addition as a function of organic framework content across RSO3H/SBA-BSTB materials.

Table 2. Catalytic performance of $\mathrm{PrSO}_{3} \mathrm{H} / \mathrm{SBA}-\mathrm{BTSB}$ catalysts in palmitic acid esterification with methanol at $60^{\circ} \mathrm{C}$.

\begin{tabular}{cccc}
\hline Catalyst & $\begin{array}{c}\text { Conversion } \\
/ \%\end{array}$ & $\begin{array}{c}\text { TOF } \\
/ \mathrm{h}^{-1}\end{array}$ & $\begin{array}{c}\mathrm{TOF} \\
\left(+\mathrm{H}_{2} \mathrm{O}\right) \\
/ \mathrm{h}^{-1}\end{array}$ \\
\hline $\mathrm{PrSO}_{3} \mathrm{H} / \mathrm{SBA}-\mathrm{BTSB} 0 \%$ & 73 & 15 & 3 \\
$\mathrm{PrSO}_{3} \mathrm{H} / \mathrm{SBA}-\mathrm{BTSB} 25 \%$ & 68 & 11 & 2 \\
$\mathrm{PrSO}_{3} \mathrm{H} / \mathrm{SBA}-\mathrm{BTSB} 50 \%$ & 86 & 14 & 4 \\
$\mathrm{PrSO}_{3} \mathrm{H} / \mathrm{SBA}$-BTSB75\% & 87 & 13 & 4 \\
$\mathrm{PrSO}_{3} \mathrm{H} / \mathrm{SBA}-\mathrm{BTSB} 100 \%$ & 94 & 12 & 5 \\
\hline
\end{tabular}

${ }^{\mathrm{a}} 6 \mathrm{~h}$ reaction
Glyceryl tripalmitate transesterification with methanol was subsequently investigated over $\mathrm{PrSO}_{3} \mathrm{H} / \mathrm{SBA}-\mathrm{BTSB}$ catalysts. In contrast to FFA esterification, Fig. 3 shows that both triglyceride conversion and TOF were linearly proportional to the framework organic content. Triglycerides are highly lipophilic, and hence their transesterification is rate-limited by protonation of the ester [26]. TAG in-pore diffusion and subsequent reaction is therefore a strong function of pore hydrophobicity, and hence incorporation of phenyl groups into the silica framework, and the resulting increase in support hydrophobicity, appears to significantly enhance tripalmitate mass-transport. Hydrophobisation may also serve to displace reactively-formed glycerol from the pore network and thereby displace the equilibrium forwards.

Methyl and butyl ester production is quantified in Fig. S21, and highlights the overwhelming selectivity of our SBA-BTSB catalysts to the desired FAME with increasing framework organic content (Table 3). This enhanced selectivity with degree of hydrophobicity could reflect the relative adsorption of methyl versus butyl groups. Indeed, IGC measurements (Fig S22) evidenced rapid methanol elution (and therefore enhanced mass-transport) through the unfunctionalised SBA-BTSB50\% parent support relative to the pure silicate SBA-BTSB0\%, whereas the reverse was observed for longer chain alkyls such as decane.

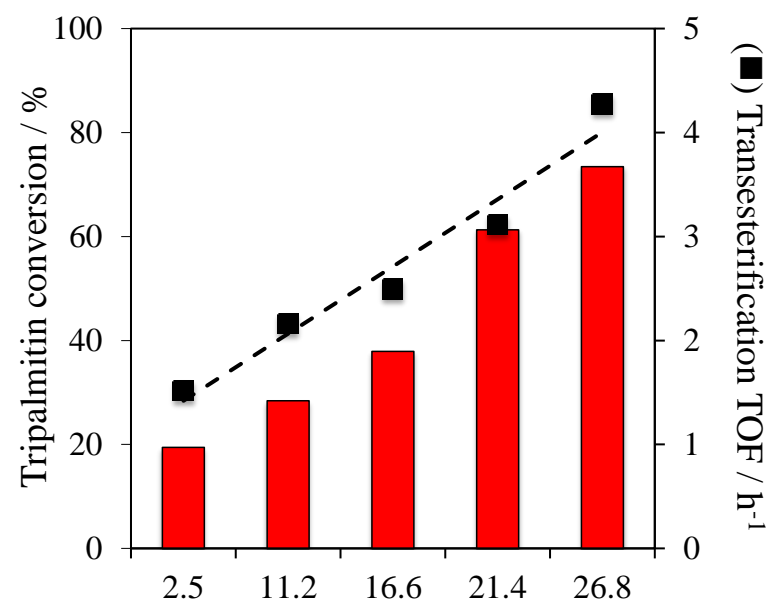

Framework carbon / wt\%

Fig. 3. Glyceryl tripalmitin transesterification with methanol at $80{ }^{\circ} \mathrm{C}$ over sulfonic acid grafted SBA-BTSB as a function of framework organic content. Data after $24 \mathrm{~h}$ reaction.

Table 3. Catalytic performance of $\mathrm{PrSO}_{3} \mathrm{H} / \mathrm{SBA}-\mathrm{BTSB}$ catalysts in glyceryl tripalmitin transesterification with methanol at $80^{\circ} \mathrm{C}$.

\begin{tabular}{cccc}
\hline Catalyst & $\begin{array}{c}\text { Conversion } \\
/ \%\end{array}$ & TOF / ${ }^{-1}$ & $\begin{array}{c}\text { FAME } \\
\text { selectivity } \\
/ \%\end{array}$ \\
\hline $\mathrm{PrSO}_{3} \mathrm{H} / \mathrm{SBA}-\mathrm{BTSB} 100 \%$ & 74 & 4 & 74 \\
$\mathrm{PrSO}_{3} \mathrm{H} / \mathrm{SBA}^{\mathrm{c}} \mathrm{BTSB} \%$ & 20 & 2 & 47 \\
$\left(\begin{array}{c}\text { Toluene) } \mathrm{PrSO}_{3} \mathrm{H} / \mathrm{SBA}- \\
\mathrm{BTSB} \%^{\mathrm{a}}\end{array}\right.$ & 8 & 0.3 & 78 \\
${\text { One-pot } \mathrm{PrSO}_{3} \mathrm{H} / \mathrm{SBA}-15^{\mathrm{a}}}$ & 12 & 0.5 & 75 \\
\hline
\end{tabular}

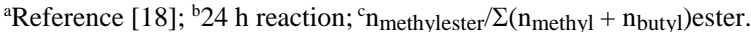




\section{Conclusions}

Sulfonic acid derivatisation of phenyl-bridged, inorganicorganic PMO hybrid materials via the HSPG method [18] affords high acid loading, hydrophobic, ordered mesoporous catalysts which are active towards FAME production via both FFA esterification and TAG transesterification with methanol. Increasing the hydrophobic character of silica frameworks via phenyl incorporation significantly improves water tolerance during palmitic acid esterification, even under extremely challenging reaction conditions of $20 \mathrm{wt} \%$ water. Systematic tuning of support hydrophobicity via organic framework modification provides a simple means to enhance the catalytic performance of sulfonic acid functionalised silicas for glyceryl tripalmitate transesterification with methanol, presumably due to increased mass-transport of the oil reactant. Additional improvements in reactivity are under investigation through the application of interconnected and hierarchical pore networks to further promote in-pore molecular diffusion for both esterification and transesterification [4-6]. Given palmitic acid and tripalmitin are the principal fatty acid and triglyceride components of palm oil respectively, we anticipate that our $\mathrm{PrSO}_{3} \mathrm{H} / \mathrm{SBA}-\mathrm{BTSB}$ catalysts will perform well against palm oil conversion, offering simultaneous conversion of $\mathrm{C}_{16}$ FFA and TAG to FAME in a single step process.

\section{Acknowledgements}

We thank the EPSRC (EP/K000616/1, EP/F063423/1 and EP/G007594/3) for financial support and a Leadership Fellowship (AFL), and the Royal Society for the award of an Industry Fellowship (KW). We also acknowledge the kind assistance of D.C. Apperley at the EPSRC UK National Solidstate NMR Service at Durham. VCS acknowledges CNPq (Conselho Nacional de Desenvolvimento Cientifico e Tecnológico) for the award of a postdoctoral scholarship.

\section{Notes and references}

Electronic Supplementary Information (ESI) available: [porosimetry data, XRD, XPS, MAS-NMR, TGA, DRIFT spectra and FFA esterification reaction profiles]. See DOI: 10.1039/c000000x/

1. Asefa T, MacLachlan MJ, Coombs N, Ozin GA (1999) Nature 402: 867.

doi:http://www.nature.com/nature/journal/v402/n6764/suppinfo/4028 67a0_S1.html

2. Su F, Guo Y (2014) Green Chemistry 16: 2934. doi:10.1039/c3gc42333f

3. Melero JA, Iglesias J, Morales G (2009) Green Chemistry 11: 1285. doi:10.1039/b902086a

4. Dacquin JP, Lee AF, Pirez C, Wilson K (2012) Chemical Communications 48: 212. doi:10.1039/c1cc14563k

5. Pirez C, Caderon J-M, Dacquin J-P, Lee AF, Wilson K (2012) ACS Catalysis 2: 1607. doi:10.1021/cs300161a

6. Dhainaut J, Dacquin J-P, Lee AF, Wilson K (2010) Green Chemistry 12: 296. doi:10.1039/b919341c
7. aMbaraka IK, Shanks BH (2005) Journal of Catalysis 229: 365. doi:http://dx.doi.org/10.1016/j.jcat.2004.11.008; bMelero JA, Bautista LF, Morales G, Iglesias J, Sánchez-Vázquez R (2010) Chemical Engineering Journal 161: 323. doi:http://dx.doi.org/10.1016/j.cej.2009.12.037

8. Dacquin J-P, Cross HE, Brown DR, Duren T, Williams JJ, Lee AF, Wilson K (2010) Green Chemistry 12: 1383. doi:10.1039/C0GC00045K

9. Inagaki S, Guan S, Ohsuna T, Terasaki O (2002) Nature 416: 304. doi:http://www.nature.com/nature/journal/v416/n6878/suppinfo/4163 04a_S1.html

10. Inagaki S, Guan S, Fukushima Y, Ohsuna T, Terasaki O (1999) Journal of the American Chemical Society 121: 9611. doi:10.1021/ja9916658

11. Melde BJ, Holland BT, Blanford CF, Stein A (1999) Chemistry of Materials 11: 3302. doi:10.1021/cm9903935

12. Hunks WJ, Ozin GA (2005) Journal of Materials Chemistry 15: 3716. doi:10.1039/b504511h

13. Van Der Voort P, Esquivel D, De Canck E, Goethals F, Van Driessche I, Romero-Salguero FJ (2013) Chemical Society Reviews 42: 3913. doi:10.1039/c2cs35222b

14. aPark SS, Santha Moorthy M, Ha C-S (2014) NPG Asia Mater 6: e96. doi:10.1038/am.2014.13; bMizoshita N, Tani T, Inagaki S (2011) Chemical Society Reviews 40: 789. doi:10.1039/COCS00010H

15. Yang Q, Liu J, Yang J, Kapoor MP, Inagaki S, Li C (2004) Journal of Catalysis 228: 265. doi:http://dx.doi.org/10.1016/j.jcat.2004.09.007

16. Morales G, Athens G, Chmelka BF, van Grieken R, Melero JA (2008) Journal of Catalysis 254: 205. doi:http://dx.doi.org/10.1016/j.jcat.2007.12.011

17. Pirez C, Lee AF, Jones C, Wilson K (2014) Catalysis Today 234: 167. doi:http://dx.doi.org/10.1016/j.cattod.2014.01.042

18. Pirez C, Lee AF, Manayil JC, Parlett CMA, Wilson K (2014) Green Chemistry 16: 4506. doi:10.1039/c4gc01139b

19. Esquivel D, Jiménez-Sanchidrián C, Romero-Salguero FJ (2011) $\begin{array}{lll}\text { Materials } & \text { Letters } & 65 \text { : }\end{array}$ doi:http://dx.doi.org/10.1016/j.matlet.2011.02.037

20. Smeulders G, Meynen V, Silvestre-Albero A, Houthoofd K, Mertens M, Silvestre-Albero J, Martens JA, Cool P (2012) Materials $\begin{array}{llll}\text { Chemistry and Physics 132: } 1077 . & \end{array}$ doi:http://dx.doi.org/10.1016/j.matchemphys.2011.12.072

21. Sánchez-Vázquez R, Pirez C, Iglesias J, Wilson K, Lee AF, Melero JA (2013) ChemCatChem 5: 994. doi:10.1002/cctc.201200527

22. Esquivel D, Jimenez-Sanchidrian C, Romero-Salguero FJ (2011) Journal of Materials Chemistry 21: 724. doi:10.1039/c0jm02980g

23. Hao N, Wang H, Webley PA, Zhao D (2010) Microporous and Mesoporous Materials 132: 543. doi:http://dx.doi.org/10.1016/j.micromeso.2010.04.008

24. Ide M, El-Roz M, De Canck E, Vicente A, Planckaert T, Bogaerts T, Van Driessche I, Lynen F, Van Speybroeck V, Thybault-Starzyk F, Van Der Voort P (2013) Physical Chemistry Chemical Physics 15: 642. doi:10.1039/C2CP42811C

25. Duan X, Liu Y, Zhao Q, Wang X, Li S (2013) RSC Advances 3: 13748. doi:10.1039/C3RA40219C

26. López DE, Goodwin Jr JG, Bruce DA (2007) Journal of Catalysis 245: 381. doi:http://dx.doi.org/10.1016/j.jcat.2006.10.027 
